\title{
Non Clinical Risk Factors of Myocardial Infarction: A Meta-Analysis Approach
}

\author{
Sajid MR ${ }^{1 *}$, Ansar $A^{2}$, Hanif $A^{3}$, Waheed $K^{4}$, Tufail $S^{2}$, Ashraf $T^{5}$ and Butt $A^{6}$ \\ ${ }^{1}$ Department of Statistics, University of Gujarat, Pakistan \\ ${ }^{2}$ University of Gujarat, Pakistan \\ ${ }^{3}$ Department of Biostatistics, Gulab Devi Post Graduate Medical Institute, Lahore), Pakistan \\ ${ }^{4}$ Department of Obstetrics and Gynecology, Lady Aitchison Unit-4, Lahore, Pakistan \\ ${ }^{5}$ Department of Public Health and Community Medicine, Combined Military Medical and Dental College, Lahore, Pakistan \\ ${ }^{6}$ Department of Medicine, King Edward Medical University Lahore, Pakistan
}

\begin{abstract}
Background: Myocardial Infarction (MI) is a coronary heart disease that is one of the main causes of the mortality over the globe. There are various clinical and non-clinical risk factors that can be further classified as modifiable and non-modifiable. This study has explored the role of the some Non Clinical factors like; Gender, Education and Family History with MI using Meta-analysis approach.

Methods: The published literature from 1990 to 2015 on Ml was collected by using several databases and search engines. A review of the collected literature (28 studies) showed that the studies under analysis were of different origins and had different objectives. For each study, Odds Ratio and $95 \%$ confidence intervals was extracted and pooled with a random effect model, weighting for the inverse of the variance. Meta-analysis software version 2.0 was used to analyze heterogeneity analysis and estimate pooled estimates through random effect model.

Results: The study has showed that gender ( $O R=1.391$ and $95 \%$ C.I.: 1.140, 1.697), family history of heart diseases $(\mathrm{OR}=3.20695 \%$ C.I.:2.064, 4.981) and low education level or illiteracy $(\mathrm{OR}=1.552$ and $95 \% \mathrm{C} . \mathrm{I.:} 1.132,2.128)$ are the significant risk factors in developing Myocardial Infarction.

Conclusion: This study has concluded that included factors in this study are significantly related to the Myocardial Infarction. Gender difference, family history of heart disease and low education are the important risk factors in causing this fatal disease.
\end{abstract}

Keywords: Myocardial infarction; Gender; Education; Family history; Risk factors; Meta-analysis

\section{Introduction}

Cardiovascular disease is a commonly used term that refers to the diseases that affect the heart and other parts of the cardiac system of the body. The cardiovascular diseases that affect the coronary arteries of the heart are called Coronary Heart Diseases (CHD) [1]. Myocardial Infarction (MI) is one of the diseases in this group. A large number of people die every year due to this fatal disease. In 2013, the number of people who died from cardiovascular disease (CVD) was more than 17.3 million (95\% uncertainty interval, 16.5 to 18.1 ), representing an increase from 1990 of $40.8 \%$ [2]. The burden of Coronary Heart Disease is increasing at a greater rate in South Asian countries than the other countries of the world. It has been estimated that the risk of MI would be doubled in the next 20 years [3]. According to American Heart Association, approximately one of every six deaths in United States is caused by MI $[4,5]$. Another study showed that the high prevalence of MI in Pakistan with more than $30 \%$ of the population over 45 years of age is affected by this disease [3]. This statistics has revealed that this disease is growing at alarming rate in the world. A mammoth literature is available on this disease. As a result many medical, social, economic, demographic risk factors were explored in the literature.

In this literature medical factors got significant attention by medical professionals and practitioners. The least attention has been paid to non-clinical factors (demographic and socioeconomic factors) which can play significant role in causing MI [6-8]. Age, gender and family history of MI are demographic factors and education is a socioeconomic factor. Age and gender has been found as powerful risk factors of MI [9]. It has also been observed that chances of getting MI increases as the age of the patients increases. Another study shows that $\mathrm{MI}$ in patients less than the age of 40 is $10 \%$ of all the cases [10]. A study conducted in Bangladesh shows that the incidence of AMI was more frequent among the patients of age group 50-59 years [11]. Recently a health survey conducted in England suggests that $4 \%$ of men and $0.5 \%$ of women have had an MI [12]; however, after the age of 70 both genders have equal chance of getting this disease. It has been observed that women have experienced their first MI on the average 9 years later than men [13].

Family history of heart diseases has also emerged as an important predictor of MI in many studies. A family history of MI increases the risk of CHD especially for MI. The National Cholesterol Education Program highlights that an individual may have a positive history of MI if his close blood relative male (father or brother) has MI younger than 55 years or female (his mother or sister) has MI younger than 65 years [14].

Socioeconomic Status (SES) refers to the combination of social and economic indicators like; education, income, occupation etc. A study

*Corresponding author: Sajid MR, Assistant Professor, Department of Statistics University of Gujarat, Pakistan, Tel: 0345-4362922; E-mail: mirzarizwansajid@gmail.com

Received July 14, 2017; Accepted August 10, 2017; Published August 22, 2017

Citation: Sajid MR, Ansar A, Hanif A, Waheed K, Tufail S, et al. (2017) Non Clinical Risk Factors of Myocardial Infarction: A Meta-Analysis Approach. J Biom Biostat 8: 363. doi: $10.4172 / 2155-6180.1000363$

Copyright: ( 2017 Sajid MR, et al. This is an open-access article distributed under the terms of the Creative Commons Attribution License, which permits unrestricted use, distribution, and reproduction in any medium, provided the original author and source are credited. 
shows that Low level of education, low income and unhealthy life style also increase the risk of MI particularly in women [15]. The current study has focused on the low education level as one of the indicators of socioeconomic status because it is very difficult to find out the income and life style subjects of the most of our collected 28 published researches. Education is generally regarded as an indicator of an individual's general knowledge and problem solving skills. Low level of education is the most consistent risk factor for MI globally [16]. It has been observed that a person who does not get education is at a greater risk of developing MI than that that gets any type of education $[17,18]$. Furthermore, education also has an inverse relation with the mortality after getting attacks of MI. It might be assumed that self-management can differ in educated person. It has been found that education level is independently and strongly associated with MI particularly among younger men [19]. In this study, there is an attempt to pool the results of different studies regarding associations of these non-clinical risk factors with MI through a Meta-Analysis Approach.

\section{Material and Methods}

The researchers have searched online databases like Medline, Pub med, Embase, Mesh etc., googled the medical subjects heading "Myocardial Infarction" and key words "Socio-economic," "Demographic", "gender as risk factor of MI", "education as a risk factor of MI", "Family History as a risk factor of MI" and "risks factor of Myocardial Infarction" to collect a corpus of 28 studies on MI.

All 28 studies were analyzed by conducting Meta-Analysis technique which matches with the inclusion criterion. It was ensured that only case control, cohort and cross sectional studies published from 1990 to 2015 on the subject MI have been taken for analysis. One of the delimitations of the study was the language of the selected research studies; as only those research studies were collected which used English as a language of their publication.

From the identified studies and respective populations characteristics of the studies were recorded which were as follows: author's name, years of publication, study design (case control study, cohort and cross sectional studies), sample size, Country of Origin, $\mathrm{RR}$ and $\mathrm{OR}$ of MI associated with socio-economic and demographic factors with their standard error.

In this study, separate Meta-analysis was performed on each risk factor of MI. All statistical analyses were performed with comprehensive Meta-analysis software version 2.0. Odds Ratio (OR) was used as effect size that reflected the magnitude of the association between different factors and the risk of MI in each study. Odds ratios with their corresponding 95\% confidence intervals (CI's) were calculated from the summary data provided. In the selected articles, researchers calculated a weighted average of odds ratio with weights being the inverse of variance of odds ratio. In the presence of heterogeneity, random effects models were used (rather than fixed effects models) to obtain pooled effect estimates across studies. Heterogeneity among the studies was studied by the inspection of $\mathrm{Q}$ statistic and $\mathrm{I}^{2}$ statistic.

\section{Results}

Initially 325 studies which followed the primary inclusion criteria were identified through different sources. Then these studies were further the scrutinized at different stages and the major portion of identified studies was excluded on the basis of; irrelevant material, inconsistency with the objectives of Meta-analysis, poor reporting, quality of work and lack of statistical data (detail is given in Flow Chart 1). Twenty eight (28) different studies were identified as potentially relevant for analysis, in the selected data of research studies 6 were

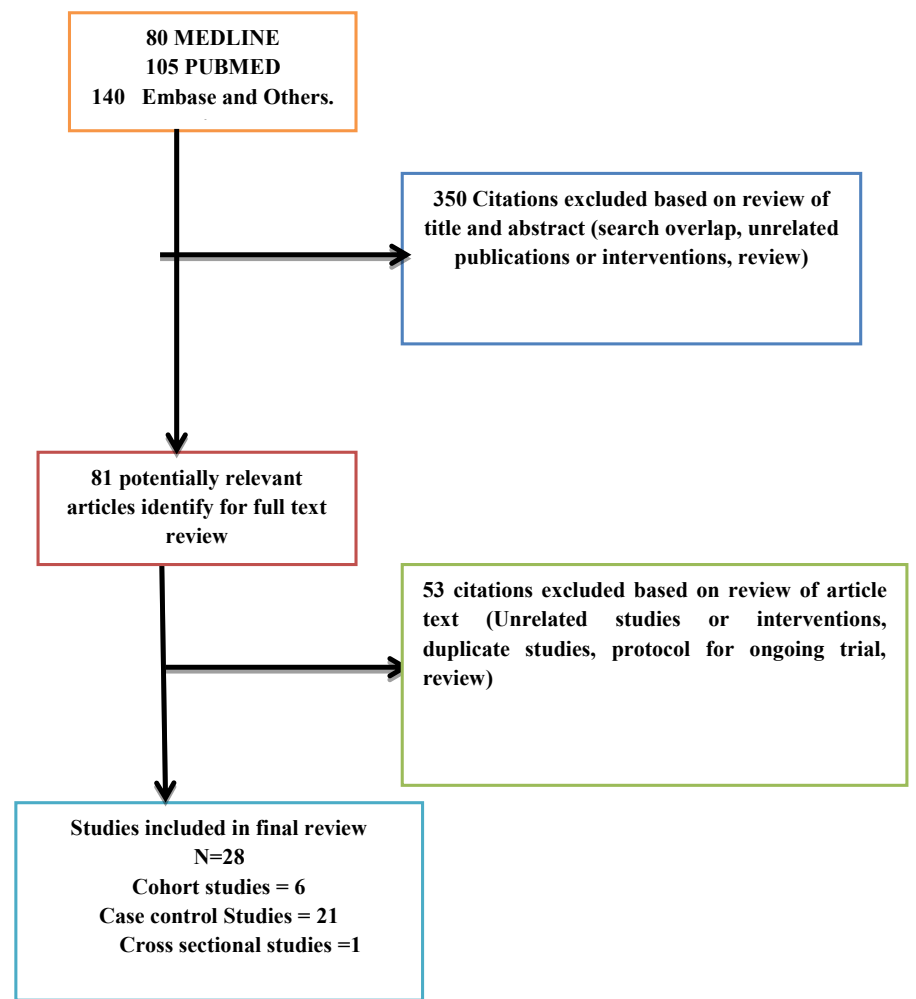

Flowchart 1: Objectives of Meta-analysis, poor reporting, quality of work and lack of statistical data. 
Citation: Sajid MR, Ansar A, Hanif A, Waheed K, Tufail S, et al. (2017) Non Clinical Risk Factors of Myocardial Infarction: A Meta-Analysis Approach. J Biom Biostat 8: 363. doi: 10.4172/2155-6180.1000363

Page 3 of 7

cohort, 1 was cross sectional and 21 were case control studies. Nineteen (19) studies had discussed the association between gender and MI. Eight (8) studies had described the association between levels of education and risk of MI. Eight (8) studies had illustrated the association between family history of heart diseases and risk of MI. The characteristics of the study subjects and the designs of the studies have been presented in Tables 1-3.

In Table 4, for all the factors, $Q$ values are significant which indicate that heterogeneity is present and values of $\mathrm{I}^{2}$ are 94.399 for gender, 92.389 for family history and 83.656 for level of education indicate that variation between studies due the real difference in the effect size. In this case random effects model has been used to pool the studies of each factor.

The pooled estimate for gender is 1.391 with $95 \%$ confidence interval of 1.140 to 1.697 . It depicts a significant association between gender and MI. It means males have 1.391 times more risk of developing MI as compared to females. The pooled estimate for family history of $\mathrm{MI}$ is 3.206 with $95 \%$ confidence interval of 2.064 to 4.981 . The pooled estimate $(\mathrm{OR}=3.206)$ indicates a highly significant connection between family history of MI and risk of MI. It portrays that the persons who have a positive family history of MI have 3.206 times more risk of MI as compared to those who do not have family history of MI. The pooled

\begin{tabular}{|c|c|c|c|c|c|c|}
\hline Study Number & $\begin{array}{c}\text { Years of } \\
\text { publication }\end{array}$ & Type of study & Country & No. of cases/ Exposed & $\begin{array}{l}\text { No. of control/Not } \\
\text { exposed }\end{array}$ & OR (95\% C.I) \\
\hline 21 & 1992 & Case control & Italy & $\begin{array}{l}801=A \\
115=B\end{array}$ & $\begin{array}{l}976=\mathrm{A} \\
130=\mathrm{B}\end{array}$ & 0.928 \\
\hline 30 & 1994 & Case control & Italy & $\begin{array}{l}542=A \\
72=B\end{array}$ & $\begin{array}{l}705=A \\
87=B\end{array}$ & 0.928 \\
\hline 31 & 1994 & Case control & Italy & $\begin{array}{l}801=A \\
115=B\end{array}$ & $\begin{array}{l}976=A \\
130=B\end{array}$ & 0.929 \\
\hline 32 & 1998 & Case control & Argentine & $\begin{array}{l}156=A \\
180=B\end{array}$ & $\begin{array}{l}228=A \\
218=B\end{array}$ & 0.829 \\
\hline 33 & 1999 & Case control & $\begin{array}{l}\text { Seattle and } \\
\text { Washington, }\end{array}$ & $\begin{array}{l}494=A \\
224=B\end{array}$ & $\begin{array}{c}1546=A \\
590=B\end{array}$ & 0.842 \\
\hline 29 & 2000 & Case control & Czech Republic & $\begin{array}{l}279=A \\
79=B\end{array}$ & $\begin{array}{r}938=A \\
1048=B\end{array}$ & 3.946 \\
\hline 34 & 2001 & Case control & New Jersey & $\begin{array}{l}440=A \\
210=B\end{array}$ & $\begin{array}{l}1269=A \\
1721=B\end{array}$ & \\
\hline 35 & 2001 & Case control & Argentine & $\begin{array}{l}734=A \\
205=B\end{array}$ & $\begin{array}{l}727=A \\
222=B\end{array}$ & \\
\hline 36 & 2005 & Cohort & Pakistan & $\begin{array}{c}88=A \\
212=B\end{array}$ & $\begin{array}{l}95=A \\
111=B\end{array}$ & \\
\hline 37 & 2005 & Case control & Spain & $\begin{array}{l}50=A \\
22=B\end{array}$ & $\begin{array}{l}39=A \\
38=B\end{array}$ & $2.21(1.13-4.33)$ \\
\hline 38 & 2006 & Case control & Japan & $\begin{array}{l}1353=A \\
572=B\end{array}$ & $\begin{array}{l}1595=A \\
684=B\end{array}$ & \\
\hline 39 & 2007 & Cohort & Pakistan & $\begin{array}{c}56=A \\
144=B\end{array}$ & $\begin{array}{l}132=A \\
368=B\end{array}$ & \\
\hline 40 & 2007 & Case control & Canada & $\begin{array}{l}10528=A \\
8825=B\end{array}$ & $\begin{array}{l}85034=\mathrm{A} \\
107787=\mathrm{B}\end{array}$ & \\
\hline 41 & 2007 & Case control & Iran & $\begin{array}{c}120=A \\
80=B\end{array}$ & $\begin{array}{c}123=\mathrm{A} \\
77=\mathrm{B}\end{array}$ & \\
\hline 42 & 2007 & Cohort & Germany & $\begin{array}{l}\text { Total } 159,120 \text { males } \\
\text { and } 39 \text { females }\end{array}$ & $\begin{array}{l}10342 \text { males and } 16453 \\
\text { females }\end{array}$ & \\
\hline 43 & 2007 & Case control & Costa Rica & $\begin{array}{l}786=A \\
103=B\end{array}$ & $\begin{array}{l}965=A \\
202=B\end{array}$ & \\
\hline 44 & 2008 & Cross sectional & Jordan & $\begin{array}{l}128=A \\
55=B\end{array}$ & $\begin{array}{l}1465=A \\
1435=B\end{array}$ & \\
\hline 45 & 2009 & Cohort & Sweden & $\begin{array}{l}34=A \\
19=B\end{array}$ & $\begin{array}{l}780=A \\
880=B\end{array}$ & \\
\hline 46 & 2009 & Cohort & Mexico & & & $1.64(0.93-2.92)$ \\
\hline
\end{tabular}

Table 1: Characteristics of the studies of which discussed gender as a Risk factor of MI. Event A: male; Event B: female.

\begin{tabular}{|c|c|c|c|c|c|c|c|}
\hline Study Number & Years of publication & Type of study & country & $<10$ years and $\mathrm{MI}$ & $\begin{array}{c}<10 \text { years and } \\
\text { NMI }\end{array}$ & $\geq 10$ years and $\mathrm{MI}$ & $\begin{array}{c}\geq 10 \text { years and } \\
\text { NMI }\end{array}$ \\
\hline 47 & 1996 & Case control & India & 135 & 116 & 65 & 84 \\
\hline 48 & 1999 & Case control & Sweden & 607 & 546 & 68 & 130 \\
\hline 49 & 2000 & Cohort & Sweden & 85 & 7443 & 3 & 1409 \\
\hline 50 & 2002 & Case control & Lithuania & 149 & 218 & 54 & 69 \\
\hline 17 & 2004 & Case control & Pakistan & 157 & 198 & 41 & 26 \\
\hline 19 & 2009 & Case control & Portuguese Caucasian & 506 & 479 & 132 & 372 \\
\hline 51 & 2009 & Case control & South Asia & 12 & 12 & 153 & 153 \\
\hline 28 & 2010 & Case control & Spain & 1224 & 1078 & 145 & 291 \\
\hline
\end{tabular}

Table 2: Characteristics of the studies which described education level as a risk of Myocardial Infarction. Event A: less than 10 years education and risk of myocardial infarction. Event B: greater than 10 years' education and risk of myocardial infarction. 
Citation: Sajid MR, Ansar A, Hanif A, Waheed K, Tufail S, et al. (2017) Non Clinical Risk Factors of Myocardial Infarction: A Meta-Analysis Approach. J Biom Biostat 8: 363. doi: 10.4172/2155-6180.1000363

Page 4 of 7

\begin{tabular}{|c|c|c|c|c|c|c|}
\hline Study Number & Years of publication & Type of study & Country & No. of cases/Exposed & $\begin{array}{l}\text { No. of control/Not } \\
\text { exposed }\end{array}$ & OR (95\% C.I) \\
\hline 31 & 1994 & Case control & Italy & $\begin{array}{l}211=A \\
705=B\end{array}$ & $\begin{array}{l}111=\mathrm{A} \\
995=\mathrm{B}\end{array}$ & \\
\hline 32 & 1998 & Case control & Argentine & $\begin{array}{l}115=A \\
221=B\end{array}$ & $\begin{array}{c}72=A \\
374=B\end{array}$ & \\
\hline 35 & 2001 & Case control & Argentine & $\begin{array}{l}308=A \\
631=B\end{array}$ & $\begin{array}{l}143=A \\
806=B\end{array}$ & \\
\hline 36 & 2005 & Cohort & Pakistan & $\begin{array}{l}119=A \\
181=B\end{array}$ & $\begin{array}{c}19=A \\
187=B\end{array}$ & \\
\hline 12 & 2005 & Case control & Spain & $\begin{array}{l}33=A \\
39=B\end{array}$ & $\begin{array}{l}34=A \\
43=B\end{array}$ & $1.07(0.56-2.04)$ \\
\hline 38 & 2006 & Case control & Japan & $\begin{array}{c}241=A \\
1684=B\end{array}$ & $\begin{array}{c}152=A \\
2127=B\end{array}$ & \\
\hline 30 & 2007 & Cohort & Pakistan & $\begin{array}{c}174=A \\
26=B\end{array}$ & $\begin{array}{l}136=A \\
164=B\end{array}$ & \\
\hline 52 & 2010 & Case control & Denmark & Total 236 & Total 463 & $2.03(0.89-4.63)$ \\
\hline
\end{tabular}

Table 3: Characteristics of the studies which discussed family history as a risk factor of MI. Event A: have family history of MI Event B: don't have family history of MI.

\begin{tabular}{|c|c|c|c|c|}
\hline Risk factors & $\begin{array}{c}\text { Number of } \\
\text { studies }\end{array}$ & $\begin{array}{c}\text { Pooled estimate and 95\% C.I and its p-value (Random } \\
\text { Effect Model) }\end{array}$ & Q-statistic with p-value & $\mathbf{I}^{\mathbf{2}}$ \\
\hline Gender & 19 & $1.391(1.140-1.697),(0.001)$ & $321.976,(0.000)$ \\
\hline Family history & 8 & $3.206(2.064-4.981),(0.000)$ & $91.975,(0.000)$ \\
\hline Education & 8 & $1.552(1.132-2.128),(0.006)$ & 92.399 \\
\hline
\end{tabular}

Table 4: Pooled estimates for gender, education and family history.

Model

Study name

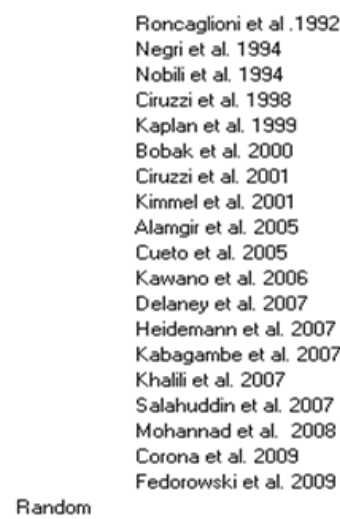

Statistics for each study

\begin{tabular}{rrrr} 
Odds ratio & Lower limit & \multicolumn{1}{c}{ Upper limit } & \multicolumn{1}{l}{ Z.Value } \\
0.928 & 0.710 & 1.213 & -0.549 \\
0.928 & 0.710 & 1.213 & -0.549 \\
0.929 & 0.667 & 1.294 & -0.435 \\
0.829 & 0.624 & 1.100 & -1.299 \\
0.842 & 0.700 & 1.012 & -1.835 \\
3.946 & 3.028 & 5.142 & 10.157 \\
1.093 & 0.881 & 1.357 & 0.811 \\
2.842 & 2.374 & 3.401 & 11.392 \\
0.485 & 0.335 & 0.702 & -3.834 \\
2.214 & 1.131 & 4.334 & 2.320 \\
1.014 & 0.888 & 1.158 & 0.211 \\
1.512 & 1.468 & 1.558 & 27.308 \\
4.895 & 3.408 & 7.031 & 8.597 \\
1.597 & 1.237 & 2.062 & 3.596 \\
0.939 & 0.629 & 1.403 & -0.307 \\
1.084 & 0.751 & 1.565 & 0.431 \\
2.280 & 1.648 & 3.153 & 4.980 \\
1.640 & 0.926 & 2.906 & 1.695 \\
2.019 & 1.142 & 3.569 & 2.417 \\
1.391 & 1.140 & 1.697 & 3.251
\end{tabular}

$$
\begin{gathered}
\text { p.Value } \\
0.583 \\
0.583 \\
0.663 \\
0.194 \\
0.067 \\
0.000 \\
0.418 \\
0.000 \\
0.000 \\
0.020 \\
0.833 \\
0.000 \\
0.000 \\
0.000 \\
0.759 \\
0.666 \\
0.000 \\
0.090 \\
0.016 \\
0.001
\end{gathered}
$$

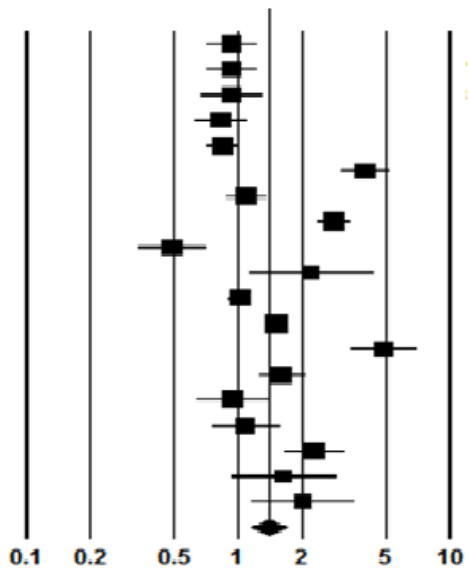

female

male

Figure 1: Summary statistic and forest plot of the studies on gender associated with risk of MI.

estimate for levels of education is 1.552 with $95 \%$ confidence interval of 1.132 to 2.128 . The pooled estimate $(\mathrm{OR}=1.522)$ shows a significant relationship between levels of education and risk of MI. It also indicates that less educated persons have 1.522 times more risk of developing MI as compared to the highly educated persons. Table 4 also shows that gender, family history of MI and levels of education are the significant risk factors for causing MI. Figures 1-3 show the odds ratios and $95 \%$ confidence intervals of MI associated with gender, family history of MI and levels of education in each study and overall respectively.

Figure 1 shows that the odds ratios of 12 studies are greater than 1 but only Nine of them are significant, and studies which overlap with the vertical line (in the center of diamond) have same effect like the overall estimate but the studies which are not overlapping with line have different effect. In this figure two studies $[12,13]$ have same effect like the overall estimate and remaining 17 studies have different effect.
Figure 2 shows that the odds ratios of all the eighth studies are greater than 1 but six studies are significant and also shows that three studies [14-16] have the same effect like the overall estimate and remaining 5 studies have different effect.

Figure 3 shows that the odds ratios of the seven studies are greater than 1 but four studies are significant and also shows that two studies $[17,18]$ have same effect like the overall estimate and other 5 other studies have different effect.

\section{Discussion}

The results of present Meta-analysis indicate that socioeconomic (Education) and demographic (Gender and Family History) factors play a significant role in the developing of MI. This study estimate $(\mathrm{OR}=1.391)$ shows that men have greater chance of developing $\mathrm{MI}$ as compared with women. 


\begin{tabular}{clrrrrr} 
Model & \multicolumn{5}{c}{ Study name } & \multicolumn{5}{c}{ Statistics for each study } \\
& & Odds ratio & Lower limit & Upper limit & Z-Value & p-Value \\
& Negri et al. 1994 & 2.683 & 2.091 & 3.442 & 7.760 & 0.000 \\
& Ciruzzi et al. 1998 & 2.703 & 1.927 & 3.791 & 5.762 & 0.000 \\
& Ciruzzi et al. 2001 & 2.751 & 2.199 & 3.442 & 8.854 & 0.000 \\
& Alamgir et al. 2005 & 6.471 & 3.826 & 10.945 & 6.963 & 0.000 \\
& Cueto et al. 2005 & 1.070 & 0.561 & 2.042 & 0.206 & 0.837 \\
& Kawano et al. 2006 & 2.003 & 1.619 & 2.478 & 6.395 & 0.000 \\
& Salahuddin et al. 2007 & 17.912 & 11.344 & 28.282 & 12.382 & 0.000 \\
& Nordestgaard et al. 2010 & 2.030 & 0.890 & 4.630 & 1.683 & 0.092 \\
Random & 3.206 & 2.064 & 4.981 & 5.183 & 0.000
\end{tabular}

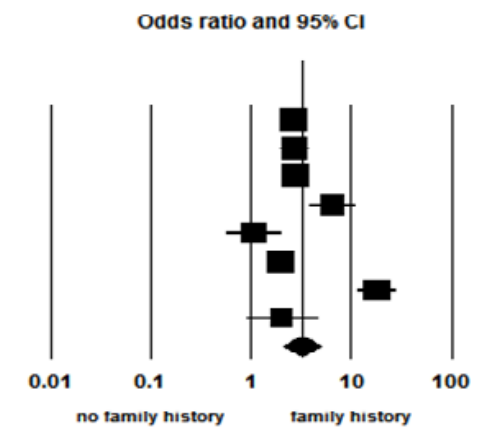

Figure 2: Summary statistic and forest plot of the studies on family history of MI associated with risk of MI.

Model

Study name

Pais et al. 1996

Huhtasaari et al. 1999

Engstrom et al. 2000

Malinauskiene et al. 2002

Ismail et al. 2004

Kumar et al. 2009

Oliveira et al. 2009

Zobl et al. 2010

Random
Statistics for each study

$\begin{array}{rrr}\text { Odds ratio } & \text { Lower limit } & \text { Upper limit } \\ 1.504 & 1.000 & 2.262 \\ 1.959 & 1.455 & 2.639 \\ 1.084 & 0.658 & 1.788 \\ 0.873 & 0.578 & 1.319 \\ 1.139 & 0.691 & 1.876 \\ 1.000 & 0.436 & 2.295 \\ 2.977 & 2.354 & 3.764 \\ 2.279 & 1.837 & 2.826 \\ 1.552 & 1.132 & 2.128\end{array}$

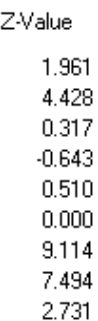

Odds ratio and $95 \% \mathrm{Cl}$

$$
\begin{gathered}
\text { p.Value } \\
0.050 \\
0.000 \\
0.751 \\
0.520 \\
0.610 \\
1.000 \\
0.000 \\
0.000 \\
0.006
\end{gathered}
$$

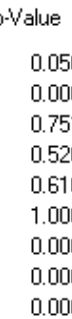

Figure 3: Summary statistic and forest plot of the studies on levels of education associated with risk of MI.

This relationship is consistent with the studies previously conducted in Asian countries as well as in the developed countries [810]. A study conducted in India [20] showed the risk of developing MI three times more among males as compared with the females. An Interheart case control study conducted in the 52 countries of the world has also shown that the women had experienced their first MI on the average nine years later than the men in all the different regions of the world [16].

The point estimate $(\mathrm{OR}=3.206)$ for Family History indicates that the person who have a strong family history of MI have greater chance of developing MI as compared with those persons who don't have a family history of MI. A study [21], on the behalf of GISSI-EFRIM, investigates the association between family history of MI and risk of AMI [22-25]. These mentioned studies have reported that Family history of heart disease was a significant and independent risk factor of MI.

In the present study the point estimate $(\mathrm{OR}=1.552)$ for education indicates that less educated persons have greater risk of developing $\mathrm{MI}$ as compared with the highly educated persons. This relationship is consistent with studies previously conducted in different regions of the world [13,16,18,26]. A study [27] describes a Meta-analysis study on the socioeconomic position and incident of AMI. It also shows that education level was strongly associated with the risk of developing MI. The risk of developing MI was greatest in individuals with only an elementary school education as compared to higher level education [28]. Personal education and parental education were also strongly associated with the risk of developing MI [29-40].

\section{Conclusion}

This study has mainly focused on the relationship of gender, education and family history with risk of MI. The study has used past researches which contain relevant data on these three selected factors [41-52]. On the basis of Meta-analysis, this study has concluded that the male are at a more risk in having MI as compared with the females. Similarly low income or low socioeconomic status also have associations with the status of MI. Family history of the heart disease is also an important risk factor in causing this fatal diseases.

\section{Acknowledgment}

The authors declare that there is no conflict of interest in doing this study.

\section{References}

1. Levick JR (2013) An introduction to cardiovascular physiology: ButterworthHeinemann.

2. Roth GA, Forouzanfar MH, Moran AE, Barber R, Nguyen G, et al. (2015) Demographic and epidemiologic drivers of global cardiovascular mortality. New England Journal of Medicine 372: 1333-1341.

3. Gaziano TA, Bitton A, Anand S, Abrahams-Gessel S, Murphy A (2010) Growing epidemic of coronary heart disease in low-and middle-income countries. Current problems in cardiology 35: 72-115.

4. Center SL (2000) Facts and figures at a glance. University of Alabama, Brimingham, Alabama.

5. Heidenreich PA, Albert NM, Allen LA, Bluemke DA, Butler J, et al. (2013) Forecasting the impact of heart failure in the United States. Circulation: Heart Failure 6: 606-619.

6. D'Onofrio G, Safdar B, Lichtman JH, Strait KM, Dreyer RP, et al. (2015) Sex differences in reperfusion in young patients with ST-segment elevation myocardial infarction: results from the VIRGO study. Circulation. 
Citation: Sajid MR, Ansar A, Hanif A, Waheed K, Tufail S, et al. (2017) Non Clinical Risk Factors of Myocardial Infarction: A Meta-Analysis Approach. J Biom Biostat 8: 363. doi: 10.4172/2155-6180.1000363

7. Chung SC, Gedeborg R, Nicholas O, James S, Jeppsson A, et al. (2014) Acute myocardial infarction: a comparison of short-term survival in national outcome registries in Sweden and the UK. The Lancet 383: 1305-12.

8. Gehani AA, Al-Hinai AT, Zubaid M, Almahmeed W, Hasani MM, et al. (2014) Association of risk factors with acute myocardial infarction in Middle Eastern countries: the INTERHEART Middle East study. European journal of preventive cardiology 21: 400-410.

9. Maggioni AA, Maseri A, Fresco C, Franzosi MG, Mauri F, et al. (1993) Agerelated increase in mortality among patients with first myocardial infarctions treated with thrombolysis. New England Journal of Medicine 329: 1442-1448.

10. Tuzcu EM, Kapadia SR, Tutar E, Ziada KM, Hobbs RE, et al. (2001) High prevalence of coronary atherosclerosis in asymptomatic teenagers and young adults. Circulation 103: 2705-2710.

11. Rahsid A, Islam MM, Islam MR (2005) Selected Risk Factors for Myocardia Infarction among the Patients Admitted in Rajshahi Medical College Hospital TAJ: Journal of Teachers Association 18: 37-42.

12. Scarborough PA, Bhatnagar $P$, Wickramasinghe K, Smolina K, Mitchell $C$, et al. (2010) Coronary heart disease statistics 2010 edition. London: British Heart Foundation 2010

13. Anand SS, Islam S, Rosengren A, Franzosi MG, Steyn K, et al. (2008) Risk factors for myocardial infarction in women and men: insights from the INTERHEART study. European heart journal 29: 932-940.

14. Grundy SM (1993) Second Report of the Expert Panel on Detection, Evaluation, and Treatment of High Blood Cholesterol in Adults: (Adult Treatment Panel li). DIANE Publishing.

15. Nyboe J, Jensen G, Appleyard M, Schnohr P (1989) Risk factors for acute myocardial infarction in Copenhagen. I: Hereditary, educational and socioeconomic factors. European heart journal 10: 910-916.

16. Rosengren A, Subramanian S, Islam S, Chow CK, Avezum A, et al. (2009) Education and risk for acute myocardial infarction in 52 high, middle and lowincome countries: INTERHEART case-control study. Heart 95: 2014-2022.

17. Ismail J, Jafar T, Jafary F, White F, Faruqui A, et al. (2004) Risk factors for non-fatal myocardial infarction in young South Asian adults. Heart 90: 259-263.

18. Joshi $P$, Islam S, Pais $P$, Reddy S, Dorairaj $P$, et al. (2007) Risk factors for early myocardial infarction in South Asians compared with individuals in other countries. Jama 297: 286-294.

19. Oliveira A, Barros H, Azevedo A, Bastos J, Lopes C (2009) Impact of risk factors for non-fatal acute myocardial infarction. European journal of epidemiology 24 $425-432$.

20. Meenakshisundaram R, Agarwal D, Rajendiran C, Thirumalaikolundusubramanian $P(2010)$ Risk factors for myocardial infarction among low socioeconomic status South Indian population. Diabetology \& metabolic syndrome 2: 32

21. Roncaglioni MC, Santoro L, D'avanzo B, Negri E, Nobili A, et al. (1992) Role of family history in patients with myocardial infarction. An Italian case-control study, GISSI-EFRIM Investigators. Circulation 85: 2065-2072.

22. Friedlander $Y$, Kark J, Stein $Y$ (1985) Family history of myocardial infarction as an independent risk factor for coronary heart disease. British heart journal 53: $382-387$

23. Lind C, Enga KF, Mathiesen EB, Njølstad I, Brækkan SK, et al. (2014) Family History of Myocardial Infarction and Cause-Specific Risk of Myocardia Infarction and Venous Thromboembolism-The Troms $\varnothing$ Study. Circulation: Cardiovascular Genetics.

24. Hoseini K, Sadeghian S, Mahmoudian M, Hamidian R, Abbasi A (2016) Family history of cardiovascular disease as a risk factor for coronary artery disease in adult offspring. Monaldi Archives for Chest Disease 70.

25. Åkesson A, Larsson SC, Discacciati A, Wolk A (2014) Low-risk diet and lifestyle habits in the primary prevention of myocardial infarction in men: a populationbased prospective cohort study. Journal of the American college of cardiology 64: $1299-1306$

26. Yusuf S, Hawken S, Ônpuu S, Bautista L, Franzosi MG, et al. (2005) Obesity and the risk of myocardial infarction in 27000 participants from 52 countries: a case-control study. The Lancet 366: 1640-1649.

27. Manrique-Garcia E, Sidorchuk A, Hallqvist J, Moradi T (2011) Socioeconomic position and incidence of acute myocardial infarction: a meta-analysis. Journal of Epidemiology and Community Health 65: 301-309.
28. González-Zobl G, Grau M, Muñoz MA, Martí R, Sanz H, et al. (2010) Socioeconomic status and risk of acute myocardial infarction. Populationbased case-control study. Revista Española de Cardiología (English Edition) 63: $1045-1053$

29. Bobák M, Hertzman C, Škodová Z, Marmot M (2000) Own education, current conditions, parental material circumstances, and risk of myocardial infarction in a former communist country. Journal of Epidemiology and Community Health 54: $91-96$

30. Nobili A, D'Avanzo B, Santoro L, Ventura G, Todesco P, et al. (1994) Serum cholesterol and acute myocardial infarction: a case-control study from the GISSI-2 trial. Gruppo Italiano per lo Studio della Sopravvivenza nell'InfartoEpidemiologia dei Fattori di Rischio dell'Infarto Miocardico Investigators. British heart journal 71: 468-473.

31. Negri E, La Vecchia C, D'Avanzo B, Nobili A, La Malfa RG (1994) Acute myocardial infarction: association with time since stopping smoking in Italy. GISSI-EFRIM Investigators. Gruppo Italiano per lo Studio della Sopravvivenza nell'Infarto. Epidemiologia dei Fattori di Rischio dell'Infarto Miocardico. Journa of Epidemiology and Community Health 48: 129-133

32. Ciruzzi M, Pramparo P, Esteban O, Rozlosnik J, Tartaglione J, et al. (1998) Case-control study of passive smoking at home and risk of acute myocardial infarction. Journal of the American college of cardiology 31: 797-803.

33. Kaplan RC, Psaty BM, Heckbert SR, Smith NL, Lemaitre RN (1999) Blood pressure level and incidence of myocardial infarction among patients treated for hypertension. American Journal of Public Health 89:1414-1417.

34. Kimmel SE, Berlin JA, Miles C, Jaskowiak J, Carson JL, et al. (2001) Risk of acute first myocardial infarction and use of nicotine patches in a general population. Journal of the American college of cardiology 37: 1297-1302.

35. Ciruzzi M, Pramparo P, Rozlosnik J, Zylberstjn H, Delmonte H, et al. (2001) Hypertension and the risk of acute myocardial infarction in Argentina. Preventive cardiology 4: 57-64.

36. Alamgir M, Salahuddin M (2005) A Statistical Study of Socio-economic and Physical Risk Factors of Myocardial Infarction. Pakistan Journal of Statistics and Operation Research 1.

37. Cueto A, Mesa F, Bravo M, Ocaña-Riola R (2005) Periodontitis as risk facto for acute myocardial infarction. A case control study of Spanish adults. Journal of periodontal research 40: 36-42.

38. Kawano H, Soejima H, Kojima S, Kitagawa A, Ogawa H (2006) Sex differences of risk factors for acute myocardial infarction in Japanese patients. Circulation Journal 70: 513-517

39. Din S, Rabbi F, Qadir F, Khattak M (2007) Statistical analysis of risk factors for cardiovascular disease in Malakand division. Pakistan Journal of Statistics and Operation Research 3

40. Delaney JA, Daskalopoulou SS, Brophy JM, Steele RJ, Opatrny L, et al. (2007) Lifestyle variables and the risk of myocardial infarction in the general practice research database. BMC cardiovascular disorders 7: 38 .

41. Khalili AA, Yaghoobi AR, Salehi R, Azarfarin R (2008) Association between Overweight and Increased Risk of Acute Myocardial Infarction. Rawal Medical Journal 33: 26-29.

42. Heidemann C, Hoffmann K, Klipstein-Grobusch K, Weikert C, Pischon T, et al (2007) Potentially modifiable classic risk factors and their impact on incident myocardial infarction: results from the EPIC-Potsdam study. European Journal of Cardiovascular Prevention \& Rehabilitation 14: 65-71.

43. Kabagambe EK, Baylin A, Campos H (2007) Nonfatal Acute Myocardial Infarction in Costa Rica. Circulation 115: 1075-1081.

44. Mohannad N, Mahfoud Z, Kanaan M, Balbeissi A (2008) Prevalence and predictors of non-fatal myocardial infarction in Jordan. East Mediterr Health J $14: 819$.

45. Fedorowski A, Burri P, Hulthen L, Melander O (2009) The metabolic syndrome and risk of myocardial infarction in familial hypertension (Hypertension Heredity in Malmö Evaluation study). Journal of hypertension 27: 109-117.

46. Jiménez-Corona A, López-Ridaura R, González-Villalpando C (2009) Incidence of myocardial infarction in low-income urban residents of Mexico City. Salud Pública de México 51: 458-464

47. Pais P, Pogue J, Gerstein H, Zachariah E, Savitha D, et al. (1996) Risk factors for acute myocardial infarction in Indians: a case-control study. The Lance 348: 358-363. 
Citation: Sajid MR, Ansar A, Hanif A, Waheed K, Tufail S, et al. (2017) Non Clinical Risk Factors of Myocardial Infarction: A Meta-Analysis Approach. J Biom Biostat 8: 363. doi: 10.4172/2155-6180.1000363

Page 7 of 7

48. Huhtasaari F, Lundberg V, Eliasson M, Janlert U, Asplund K (1999) Smokeless tobacco as a possible risk factor for myocardial infarction: a population-based study in middle-aged men. Journal of the American college of cardiology 34 1784-1790.

49. 49. Engström G, Tydén P, Berglund G, Hansen O, Hedblad B, et al. (2000) Incidence of myocardial infarction in women. A cohort study of risk factors and modifiers of effect. Journal of Epidemiology and Community Health 54: 104-107.

50. Malinauskiene V, Grazuleviciene R, Nieuwenhuijsen M, Azaraviciene A (2002)
Myocardial infarction risk and occupational categories in Kaunas 25-64 year old men. Occupational and environmental medicine 59: 745-750.

51. Kumar A, Sivakanesan R, Nagtilak S (2009) Behavioral pattern, life style and socio economic status in elderly normolipidemic acute myocardial infarct subjects-a case control study from South Asia. Internet J Cardiovasc Res 6

52. Nordestgaard BG, Adourian AS, Freiberg JJ, Guo Y, Muntendam P, et al (2010) Risk factors for near-term myocardial infarction in apparently healthy men and women. Clinical chemistry 56: 559-567. 